\title{
Demarcações epistemológicas dos estudos de citação: concepção sociocultural das citações
}

Murilo Artur Araújo da Silveira

Doutor em Comunicação e Informação (UFRGS). Professor do Departamento de Ciência da Informação (UFPE)

Sônia Elisa Caregnato

Doutora em Information Studies (University of Sheffield). Professora do Departamento de Ciências da Informação (UFRGS)

http://dx.doi.org/10.1590/1981-5344/3125

Revela as demarcações epistemológicas que configuram os estudos de citação na contemporaneidade. Parte-se do pressuposto de que os contextos sociais e culturais são vitais no desenvolvimento dos estudos de citação, na medida em que eles formalizam a relação entre a produção e as práticas de citação. Tem como objetivo propor o delineamento epistemológico inicial para uma concepção sociocultural das citações, com ênfase na explicitação das influências dos múltiplos contextos nos processos de produção e citação dos cientistas. Apresenta e discute os componentes científicos para a concepção sociocultural das citações, de natureza complementar às teorias das citações. Sugere uma matriz epistemológica para os estudos de citação e também um modelo multidimensional analítico para futuras investigações. Conclui que a concepção sociocultural pode ser aplicada metodologicamente, de forma complementar, em pesquisas que problematizem a relação estabelecida entre produção e citação.

Palavras-chave: Estudos de Citação. Epistemologia. Teorias das Citações. Concepção Sociocultural das Citações. 


\title{
Epistemological demarcations of citation studies: sociocultural conception of citation
}

\begin{abstract}
It is the third part of the epistemological demarcations that configure the citation studies in the contemporaneity. It is based on the assumption that social and cultural contexts are vital in the development of citation studies, since they formalize the relationship between production and citation practices. It aims to propose the initial epistemological design for a sociocultural conception of the citations, with emphasis on the revelation of the influences of the multiple contexts in the processes of production and citation of the scientists. It presents and discusses the scientific components for the sociocultural conception of citations, complementary in nature to the theories of citations. It suggests an epistemological matrix for citation studies and also a multidimensional analytical model for future investigations. It concludes that the sociocultural conception can be applied methodologically, in a complementary way, in researches that problematize the established relationship between production and citation.
\end{abstract}

Keywords: Citation Studies. Epistemology. Theories of Citation. Sociocultural Conception of Citation.

Recebido em 20.04.2017 Aceito em 05.02.2018

\section{Introdução}

A admissão de que os estudos de citação podem evidenciar as formas de produção e as instâncias de consagração na ciência, trazem a possibilidade de substanciar teórica e metodologicamente tais estudos. A literatura especializada distingue duas importantes teorias para os estudos de citação: a normativa e a construtivista. A distinção entre as duas propostas teóricas para os estudos está fundamentada nos seguintes pressupostos:

a) teoria normativa: ampara-se na ideia da ciência como uma instituição governada por práticas de citação resultantes de dívidas intelectuais, recompensas e sanções internas, com base nos preceitos mertonianos e livre de interferências sociais e culturais externas (LEYDESDORFF, 1998; NICOLAISEN, 2007); 
b) teoria construtivista: sustenta-se nas complexas e multivariadas razões de citações dos cientistas, com base no efeito persuasivo promovido pela apropriação e uso do conhecimento que derivam das práticas de citação (BORNMANN; DANIEL, 2008; ERIKSON; ERLANDSON, 2014).

As duas correntes teóricas, apesar de contemplarem amplamente os fenômenos relacionados às citações e referências, não conseguem responder de forma convincente os problemas que se dedicam, estando sempre a mercê de críticas e questionamentos negativos (BORNMANN; DANIEL, 2008). A literatura enfatiza que as concepções epistemológicas das duas teorias carecem de discussões que destaquem os elementos que antecedem a materialização das práticas de citação, de forma a subsidiar o entendimento dos resultados de forma contextualizada conforme a dinâmica dos campos e domínios científicos. Para Bornmann e Daniel (2008) as teorias normativa e construtivista não conseguem explicar, na maioria dos casos, as dimensões produtiva e discursiva provenientes do circuito estabelecido entre as recompensas e dívidas intelectuais e os efeitos persuasivos que sustentam as análises, respectivamente. Os autores ainda salientam que, apesar das críticas às duas proposições teóricas, a normativa apresenta resultados mais consistentes aos da construtivista, quando contrastadas as dimensões analíticas de observação dos objetos enquanto fenômenos socialmente construídos na ciência.

No tocante à pluralidade das práticas que evidenciam esses fenômenos no âmbito da Comunicação Científica, é necessário destacar a importância dos contextos sociais e culturais no desenvolvimento dos estudos de citação. Leydesdorff e Wouters (1999) enfatizam que há uma forte ligação entre texto e contexto, formalizada pela relação entre produção e citação (e referenciação) que contribuem e impulsionam, de um lado, e dificultam e limitam, do outro, a compreensão sobre determinados aspectos que envolvem os fenômenos existentes e estudados pelas teorias vigentes. Riviera (2013) defende que os diversos contextos dos pesquisadores influenciam suas práticas de citação, sobretudo quando eles buscam convencer, refutar e/ou ignorar, mas também quando impõem e/ou manipulam os elementos simbólicos que eles têm ou exercem controle científico. Nesse contexto, o conjunto de práticas relacionadas à produção e comunicação do conhecimento se torna suscetível às circunstâncias do momento, das correntes teóricometodológicas vigentes e das posições ideológicas dos diversos grupos e segmentos sociais da ciência.

Os pontos apresentados e discutidos acerca do alcance e dos limites epistemológicos das teorias das citações, a questão de pesquisa é: quais os elementos determinantes para a demarcação dos contextos sociais e culturais que repercutem nas práticas de citação produção e citação? Parte-se do pressuposto de que os contextos sociais e culturais são vitais no desenvolvimento dos estudos de citação, na medida em que eles 
formalizam a relação entre a produção e as práticas científicas em virtude das realidades existentes e/ou das correntes teórico-metodológicas vigentes (LEYDESDORFF; WOUTERS, 1999; RIVIERA, 2013; ERIKSON; ERLANDSON, 2014). Portanto, a concepção a ser delineada se reporta à análise da dimensão dos contextos sociais e culturais que definem as circunstâncias e operações realizadas pelos cientistas que resultam em atos de citação e referenciação nas contribuições científicas registradas.

Nesses termos, esta contribuição tem como objetivo central propor o delineamento epistemológico inicial para uma concepção sociocultural das citações, com ênfase na explicitação das influências dos múltiplos contextos nos processos de produção e citação dos cientistas. A proposição de delineamento teórico que se pretende considera a convivência entre as teorias, por entender que elas não se substituem por completo, mas coexistem em regime de disputa, conforme se apresenta a dinâmica plural e complexa que circundam as práticas de citação. Também pretende ser uma proposta de demarcação teórica inicial que subsidie as teorias existentes, servindo de base para a explicação dos fenômenos estudados por aquelas, já que ambas necessitam de análises contextuais da dinâmica de produção e comunicação do conhecimento dos campos e domínios científicos.

Portanto, justificativa central desta pesquisa se sustenta na proposição teórico-epistemológica inicial com foco analítico das dimensões dos contextos sociais e culturais que definem as circunstâncias e operações realizadas pelos cientistas que resultam em atos de citação e referenciação nas contribuições científicas registradas. Integra um conjunto de contribuições que visam à demarcação teórica dos estudos de citação, com justificativa essencialmente teórica e científica, de forma a ampliar a base epistemológica dos estudos de citação. Configura-se, então, como uma pesquisa de natureza bibliográfica e exploratória que se pauta na intersecção de contribuições dos estudos sociais da ciência, buscando complementar as explicações dos fenômenos estudados, com análises contextuais da dinâmica de produção e comunicação do conhecimento.

\section{As práticas de citação e os contextos socioculturais}

A concepção sociocultural dos estudos de citação está orientada para evidenciar e explicar as influências que os múltiplos contextos exercem nas relações existentes entre produção e citação, bem como a repercussão dessa influência para os campos e domínios científicos. Os objetos de análise desta concepção são os contextos culturais direcionados para os processos que constituem as conexões entre as práticas de citação e de produção científica. A identificação e a análise da lógica de reprodução social baseada nas formas de consagração no universo da ciência é o objetivo central desta concepção teórica, entendendo que as relações de força e de poder exercidos pelos atores, grupos e instituições interferem nas formas de citar e produzir. Esse enfoque tem a intenção de apresentar a trajetória histórico-cultural que 
permeia as ações dos praticantes da ciência, com vistas à análise crítica das realizações significativas que apontam os avanços e retrocessos, as marcas e filiações filosóficas e científicas e as posições sociais e ideológicas.

A concepção delineada, antes de tudo, deve ser compreendida e aplicada de forma complementar às teorias vinculadas aos estudos de citação, com demarcações claras de suas aproximações e distinções epistemológicas. Voltada para as influências culturais que afetam as formas de produção e citação, a perspectiva teórica complementar apontada é defendida com o propósito de fornecer outros elementos não contemplados nas teorias vigentes anteriormente discutidas. Enquanto sugestão de postulado epistemológico, esta concepção se ampara em formulações teóricas críticas vinculadas à compreensão de contextos que repercutem nos processos de apreensão, produção, organização, comunicação e utilização do conhecimento científico.

Para tanto, torna-se oportuno esclarecer que a concepção sociocultural não é uma continuidade do enfoque construtivista, na medida em que busca a compreensão dos contextos; trata-se, desta forma, de uma formulação teórica e metodológica que busca amplificar a dimensão da citação para além do texto, do discurso e da contribuição científica, com o propósito de elevar todos os contextos que interferiram no ato de citar (DAVIS, 2009; ERIKSON; ERLANDSON, 2014). Mais ainda, a concepção sociocultural tem o propósito de problematizar a ação produtiva que afeta os campos científicos, no sentido de ilustrar que as práticas decorrentes do processo sinalizam relações mercantis que mobilizam a formação de grupos, discriminam valores e significados e instauram o mercado de trocas simbólicas (BOURDIEU, 2011b). No espaço das disputas mercantis e simbólicas, as relações de poder provocam ações discriminatórias na concepção e viciadas na execução das práticas de citações, alterando condutas sociais e perpetuando posições ideológicas.

Para delimitar o alcance do objeto do enfoque sociocultural, consideram-se as contribuições de Leydesdorff e Wouters (1999), Wouters (1999), Leydesdorff (2001), Lievrouw (2001) e Riviera (2013) para demarcação do conceito de contexto cultural. Nesse sentido, contexto cultural para o enfoque sociocultural das citações compreende o conjunto de elementos evidentes e subjacentes e suas conexões com os interesses e conflitos sociais presentes no fazer científico, relacionados com as práticas que demarcam as escolhas dos pesquisadores, nas perspectivas histórica, política, social, ética e cognoscitiva. Os resultados provenientes dos contextos culturais dos estudos de citação do enfoque sociocultural são:

a) a demarcação das posições conquistadas e almejadas pelos grupos antagônicos que protagonizam os conflitos;

b) a contradição das ações e a incoerência das justificativas discursivas que se substanciam e se fragilizam diante do capital científico acumulado; 
c) as relações de força que buscam conjugar a distinção conferida, o alinhamento científico definido e os interesses e valores compartilhados pelos segmentos sociais que compõem o campo científico; e

d) o estabelecimento das trocas mercantis de natureza simbólica que constitui o efeito persuasivo das práticas individuais e coletivas e a lógica produtiva da edição certificada.

Antes de apontar como os múltiplos contextos influenciam as práticas de citação dos cientistas, torna-se necessário demarcar a noção acerca do termo contexto que será utilizada. Cool (2001) destaca que contextos são estruturas de significado compartilhadas por um sistema social e formadas por uma ou mais situações que, neste caso, são circunstâncias dinâmicas que geram processos interpretativos que compõem um ou mais contextos. Para Courtright (2007), os estudos no âmbito da Ciência da Informação costumam não perceber as diferenças entre contexto e situação, salientando que um contexto deve ser compreendido como um conjunto de situações dependente da ação dos atores e de fatores externos, delimitado e reorganizado na ambiência da continuidade das práticas de informação. Salienta ainda o autor que as discussões sobre o tema são realizadas de forma equivocada, sem problematização e compreensão das variáveis e situações necessárias para a delimitação dos contextos, com prejuízos conceituais, técnicometodológicos e interpretativos das práticas de informação.

Diante da variedade de modelos conceituais que buscam estabelecer os contextos culturais diretamente relacionados às práticas de informação, - modelo de Lievrouw (2001) será utilizado para a configuração e discriminação dos contextos que influenciam as práticas de citação dos cientistas. É importante registrar, todavia, que o princípio norteador para a caracterização dos contextos que permeiam a atividade científica se operacionaliza pelas conexões que os atores realizam entre os significados das práticas sociais e as situações que determinam as práticas de citação. No conjunto dos múltiplos contextos que influenciam e permitem a objetivação das práticas de citação, exibe-se o Quadro 1 que sistematiza o panorama entre os dois elementos.

Quadro 1 - Contexto das práticas de citação

\begin{tabular}{c|c}
\hline Contextos & Especificidades dos Contextos e Situações \\
\hline \multirow{2}{*}{ Orgânicos } & Formação Acadêmica \\
\cline { 2 - 2 } Epistêmicos & Atuação Profissional \\
\cline { 2 - 2 } & Tradição Científica \\
\cline { 2 - 2 } & Especialidade Temática \\
\hline \multirow{2}{*}{ Sociopolíticos } & Vinculação a Grupos Teóricos e Metodológicos \\
\cline { 2 - 2 } & Vinculação Sorreção Científicas \\
\cline { 2 - 2 } & Relações Sociogeográficas e/ou Institucional \\
\hline
\end{tabular}

Fonte: Elaborado pelos Autores (2016). 
Wouters (1999) e Riviera (2013) complementam que as dimensões social e ética estão atreladas a todo e qualquer contexto em uma perspectiva transversal de observação e análise, validando ou deturpando as práticas vigentes e salvaguardadas pela comunidade, em que as consequências só podem ser dimensionadas em um tempo futuro. Contudo, é importante ressaltar que outros contextos podem existir além dos apresentados no quadro, pois como expressam Leydesdorff e Wouters (1999), a natureza dos contextos é diretamente proporcional à intensidade e pluralidade das práticas, com reflexos diretos na produção e uso da informação, justificadas pela obrigatoriedade das menções bibliográficas nos textos científicos. Pontuam também os autores que outros contextos podem surgir, devido às especificidades das descobertas e às interferências recebidas pelos atores no processo de comunicação entre os pares. Em suma, os contextos culturais para a concepção sociocultural procuram sinalizar os mecanismos de reprodução social, situar as instâncias de consagração e evidenciar os componentes ideológicos que fundamentam a relação entre as citações e a produção da ciência.

Ao considerar a relevância dos contextos culturais nas ações humanas e sociais, Thompson (1995) indica que todas as práticas realizadas pelo homem são conduzidas (incluindo as científicas), em maior ou menor grau, por um sistema de ideias organizado na mente que conformam os interesses pessoais e coletivos, estando subjacentes aos da sociedade. Essas conformações - também conhecidas como ideologias procuram se alinhar com o propósito de congregar os interesses e as práticas sociais, para que indivíduo e sociedade se harmonizem em um único propósito. Porém, o autor aponta que por conta da diversidade de ações, os interesses individuais e coletivos se chocam, acarretando processos conflituosos entre as partes e favorecendo o surgimento das ideologias.

Por conta dos conflitos, os indivíduos com interesses comuns se organizam em grupos para cultivar suas práticas, estabelecendo, segundo Thompson (1995), os seus componentes ideológicos. As organizações dos diversos segmentos sociais avançam e recuam em função da articulação entre seus integrantes e dos níveis relativos de capital científico acumulado. Desse processo, as classes sociais se constituem com base no capital científico, em maior ou em menor densidade, instituindo os regimes de dominação, e consequentemente as desigualdades das disputas entre dominantes e dominados (THOMPSON, 1995; BOURDIEU, 2013). Conforme Bourdieu (1983; 2011a), os conflitos entre os grupos sociais são pautados na imposição de valores e crenças socialmente compartilhados no bojo das transformações socioculturais. Como resultado tem-se a cristalização das ações e atitudes dos indivíduos em sociedade, determinando as bases das representações sociais e acionando os mecanismos existentes de reprodução social (THOMPSON, 1995).

Contudo, há uma importante consideração a ser feita sobre a formação dos grupos e os mecanismos de reprodução social no tocante às práticas que se incorporam ao fazer científico, conforme conveniências em 
torno de correções, alterações, imposições, que intencionam a configuração e reconfiguração dos agenciamentos instituídos. Para Bourdieu (2004; 2011a; 2013), os agenciamentos conduzidos pelos atores científicos decorrem das posições alcançadas por eles, objetivam não somente a manutenção das posições alcançadas e dos valores, crenças e regras de conduta e de pesquisa, mas a perpetuação de grupos e segmentos sociais historicamente favorecidos. Tais agenciamentos, segundo 0 autor, se amparam em contextos socioculturais que possibilitam conformar as convergências e divergências dos interesses dos integrantes destes grupos para alinhamento das disputas travadas e dos acordos firmados, em consonância com a vitalidade e a força dos capitais científicos e políticos alcançados. Do panorama descrito em que os contextos socioculturais são determinantes para sua efetivação, resultam confrontos desiguais entre dominantes e dominados, com refração e/ou imposição de ideias e valores que incidem diretamente no conjunto de práticas científicas.

Feitas todas as considerações sobre os contextos sociais e culturais que se direcionam para as práticas de citação, evidencia-se, por meio da Figura 1, as três modalidades de análise que sustentam a concepção sociocultural dos estudos de citação.

Figura 1 - Dimensões da Concepção Sociocultural dos Estudos de Citação

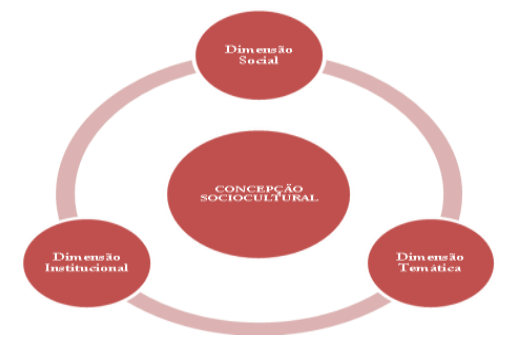

Fonte: Elaborado pelos Autores (2016).

A figura esquematiza as dimensões que fundamentam a concepção sociocultural dos estudos de citações, com o propósito de complementar as lacunas analíticas das teorias normativa e construtivista. Tal concepção está baseada na integração das dimensões que a compõem, em que os contextos possam ser entendidos por três vias: social, institucional e temática. O nível de complementaridade da concepção sociocultural às teorias existentes pode ser operacionalizado e visualizado pela utilização isolada ou integrada das dimensões para explicitar como se processam os mecanismos de reprodução social e definir as estruturas das instâncias de distinção.

\section{Concepção sociocultural das citações e as relações entre produção e distinção}

Para a apresentação dos elementos que estabelecem a configuração das dimensões da concepção sugerida, pontua-se que base teórica está pautada em articulações propostas por Bourdieu (1983; 2004; 2011a; 
2011b; 2013), Bourdieu e Passeron (2012) e Thompson (1995). Trata-se de contribuições que discutem e problematizam as formas de produção, comunicação e utilização da ciência, com percepções críticas desses efeitos, em especial aos consagradores e reprodutores, além dos aspectos ideológicos e hegemônicos que repercutem nos processos destacados. Registra-se também que as contribuições de Cronin (1981; 1984; 1998), Leydesdorff (1987; 1998; 2001; 2010), Leydesdorff e Wouters (1999) e Wouters (1999) foram igualmente incorporadas ao quadro teórico que sustenta o delineamento da concepção e suas dimensões analíticas. $O$ segundo grupo de autores destacados foi importante porque lançaram ideias e conceitos que possibilitaram determinar o conjunto de elementos que caracterizam a matriz epistemológica da concepção sociocultural (objetos, objetivos, variáveis, métodos e técnicas e resultados esperados). Desta feita, registra-se oportunamente que a configuração teórica sociocultural para os estudos de citação está amparada na literatura especializada em uma perspectiva crítica acerca das compreensões sistematizadas e disseminadas pelos autores apontados acima.

A dimensão social da concepção que ora se apresenta se pauta nas relações sociais e suas repercussões que os cientistas firmam ao longo de sua jornada científica, desde a formação até a aposentadoria, que incidem na relação entre produção e citação. Tem como objetivo principal posicionar o pesquisador em suas redes de relacionamentos sociais, os níveis e as circunstâncias das relações e as influências de sua trajetória no campo ou domínio. As posições ocupadas por esses atores costumam variar, a depender da configuração das situações concretas que resultam na produção de textos e nas formas de citar. A determinação das posições dos atores na rede é diretamente dependente da proximidade entre eles, devido às relações hierárquicas socialmente estabelecidas e aos níveis de influências e participação nos grupos cientificamente constituídos.

Em uma perspectiva crítica de análise da dimensão social da concepção sociocultural, o ponto sensível que circunda o objeto é a posição do ator nas relações sociais historicamente construídas, tendo em vista a distinção dos modos de dominação vigentes e as formas de colaboração aceitas. Por seus turnos, os modos de dominação e as formas de colaboração estão intimamente conectados por serem representações das forças hegemônicas e das coerências e contradições ideológicas que conduzem as políticas científicas aplicadas aos campos e domínios. Juntos, esses fenômenos confirmam a lógica científica conhecida como efeito mateus da ciência, que reforçam e legitimam um conjunto de práticas impostas aos atores desde o início de sua jornada, introduzindo-o em um sistema marcado por ideologias institucionais e sociais que, dentre outras possibilidades, repercutem nas formas de produzir e citar.

A dimensão institucional da concepção sociocultural voltada aos estudos de citação se orienta na demarcação da trajetória científica dos atores e as posições institucionais e disciplinares conquistadas. Tem como objetivo definir as influências recebidas pelos cientistas em sua formação e atuação acadêmica e como se processam tais influências nas práticas 
científicas que regulam o binômio produção-citação, situadas no tempo e no campo. Considera que o percurso trilhado pelos atores científicos determina a dinâmica das operações científicas realizadas, transmitidas e compartilhadas com os seus pares, em uma perspectiva sociocultural de produção, comunicação e uso do conhecimento. Evidencia as marcas das contribuições efetuadas pelos cientistas às instituições que se vinculou e ao campo que está inserido, baseada na lógica de integração de saberes construídos e práticas vivenciadas. Busca situar os reflexos da formação obtida e a atuação exercida, em um ambiente dialógico entre suas filiações teóricas e metodológicas e práticas científicas, com considerações éticas, políticas, sociais e cognoscitivas.

A pauta reivindicada pela dimensão institucional da concepção sociocultural pretende revelar a posição do ator científico e os recursos construídos em sua trajetória no campo, as certificações institucionais atribuídas e o prestígio científico conquistado. O estabelecimento das posições alcançadas é para demarcar as influências epistemológicas recebidas, assim como o repasse dessas, tomando sempre por base às instituições e os demais integrantes dos campos e domínios. No decurso analítico dessas posições, evidenciam-se as formas e os mecanismos de reprodução social que se materializam no processo educacional em suas múltiplas possibilidades, assim como o conjunto de práticas vinculadas e o escopo do repertório de saberes elaborados e sedimentados no tempo pretérito e nas instituições sociais.

Torna-se imperativo apontar que os processos de formação e atuação dos cientistas são integralmente marcados por relações simbólicas de dominação e dependência, com mudanças sensíveis de papéis que são determinadas pelas instituições no curso das realizações científicas. Visualizam-se nesse quadro de referências institucionais simbólicas as instâncias de consagração e os mecanismos de reprodução social, socialmente desenvolvidas e legitimadas, que se cristalizam e se perpetuam. No tocante às práticas científicas relacionadas ao binômio produção-citação, elas são evidentes nas circunstâncias que rodeiam os ritos e as etapas de transmissão de saberes no processo de formação dos cientistas e estão marcadas pelas relações de força e de poder exercidos pelos praticantes nos níveis macro e micro de compreensão do campo ou domínio.

Por fim, a dimensão temática que reveste a configuração da concepção sociocultural dos estudos de citação se direciona à contextualização das conexões entre a dimensão discursiva efetivada nos textos (enfoque construtivista) e a dimensão produtiva emanada das pesquisas (enfoque normativo). Tem como objetivo central a demarcação da especialidade temática que ampara a relação indissociável entre citações e referências, em consonância com o estatuto teórico e epistemológico consolidado pelo campo ou domínio. Posiciona tematicamente o pesquisador, seu percurso trilhado, as investigações desenvolvidas, as influências recebidas e exercidas por ele e as características e filiações epistemológicas enquanto agentes ativos do campo. Explicita o nível das conexões e intertextualidades efetuadas 
interna e externamente pelo campo, em um quadro de referências temáticas guiado por princípios de singularidade, expressividade e especialidade, conforme aproximações técnicas, justaposições disciplinares e conveniências sociais.

Para a dimensão temática, o conjunto de operações e práticas científicas em um campo reflete o modus operandi da consolidação de seus recortes temáticos e expressa a dinamicidade das formas de registro das citações e referências sob a vigilância das instâncias de distinção e dos mecanismos de reprodução social. Os processos de entrada, permanência, crescimento e saída no campo e em suas especialidades temáticas devem obedecer aos ritos institucionais e sociais que, embora costumem ser valorizados e criticados, são os instrumentos que orientam a criação e manutenção dos elementos balizadores de pertencimento e reconhecimento historicamente construídos. Neste horizonte de análise, as práticas de citação e referenciação realizadas em conformidade com o aval de cientificidade estabelecido pelos praticantes do escopo temático, cristalizadas e propagadas, repercutem positiva ou negativamente: a) em ações e atitudes coerentes e pertinentes que considerem as múltiplas possibilidades que caracterizam a apreensão e utilização do conhecimento produzido; b) em posturas e condutas contraditórias que não concretizem os avanços teóricos e epistemológicos necessários; e c) em parâmetros e outras medidas de controle que impedem transgressões científicas, paradigmáticas, institucionais e sociais.

A apresentação das características que definem as três dimensões da concepção teórica sugerida enfatiza o nível de complexidade que incide na visualização e delimitação dos contextos socioculturais enquanto enfoque analítico para os estudos de citação. Em linhas gerais, tais contextos podem ser percebidos por meio das seguintes relações:

a) dimensão social

relações sociais entre autores produtores e citados;

relações sociais entre instituições produtoras e citadas;

b) dimensão institucional

relações institucionais de formação entre autores produtores e citados;

relações institucionais de atuação entre autores produtores e citados;

c) dimensão temática

relações de proximidade temática entre autores produtores e citados;

relações de distanciamento temático entre autores produtores e citados.

É oportuno enfatizar que as análises das relações também consideram outros elementos vinculados aos objetivos das dimensões, 
sobretudo àqueles que se reportam à autoria, às citações e referências, entre outros. Do ponto de vista simbólico, as três dimensões focam os aspectos evidentes e subjacentes da lógica que subsidia e determina os confrontos sociais, institucionais e temáticos travados, pautados nos elementos simbólicos da atividade científica por meio do binômio produção-citação. A integração entre os aspectos contemplados pelas dimensões da concepção sociocultural possibilita realizar análises verticalizadas e complementares sobre as situações e os contextos que delimitam e demarcam as formas de produção, situam e discriminam as instâncias de distinção, explicitam e reforçam os mecanismos de reprodução social. As configurações das situações e dos contextos, em larga escala e amplitude, resultam da conjugação e conformação entre as disputas ideológicas entre os agentes e as relações de dominação provenientes das posições alcançadas. Pontua-se também que o arranjo relacional sugerido entre as três dimensões intenciona sinalizar como as forças e os poderes exercidos pelos cientistas e seus grupos influenciam na determinação, consolidação e perpetuação do conjunto de instrumentos que demarcam as posições ideológicas hegemônicas na produção, comunicação e utilização do conhecimento científico.

As estruturas elementares que estruturam as três dimensões sugeridas para a concepção sociocultural dos estudos de citação são contempladas a partir do Quadro 2 que apresenta sua matriz epistemológica.

Quadro 2 - Matriz epistemológica da concepção sociocultural dos estudos de citação

\begin{tabular}{|c|c|c|c|}
\hline \multirow{2}{*}{$\begin{array}{l}\text { Concepção } \\
\text { Sociocultural }\end{array}$} & \multicolumn{3}{|c|}{ Descrição das Dimensões } \\
\hline & $\begin{array}{c}\text { Dimensão } \\
\text { Social }\end{array}$ & $\begin{array}{c}\text { Dimensão } \\
\text { Institucional }\end{array}$ & $\begin{array}{l}\text { Dimensão } \\
\text { Temática }\end{array}$ \\
\hline Objetos & $\begin{array}{l}\checkmark \quad \text { Relações sociais } \\
\text { entre os autores } \\
\text { produtores e citados }\end{array}$ & $\begin{array}{l}\checkmark \quad \text { Relações } \\
\text { institucionais entre os } \\
\text { autores produtores e } \\
\text { citados }\end{array}$ & $\begin{array}{l}\checkmark \quad \text { Relações temáticas } \\
\text { entre os autores } \\
\text { produtores e citados }\end{array}$ \\
\hline Variáveis & $\begin{array}{l}\checkmark \quad \text { Elementos e fatores } \\
\text { vinculados à autoria e } \\
\text { suas manifestações } \\
\text { (teoria normativa) }\end{array}$ & $\begin{array}{l}\checkmark \quad \text { Elementos e fatores } \\
\text { vinculados à formação e } \\
\text { atuação institucional e } \\
\text { suas manifestações } \\
\text { (teoria normativa) }\end{array}$ & $\begin{array}{l}\checkmark \quad \text { Elementos e fatores } \\
\text { vinculados aos recortes } \\
\text { temáticos e às } \\
\text { manifestações existentes } \\
\text { entre autores produtores } \\
\text { e citados (teoria } \\
\text { construtivista) }\end{array}$ \\
\hline Objetivos & $\begin{array}{l}\checkmark \quad \text { Demarcar os } \\
\text { vínculos e efeitos sociais } \\
\text { decorrentes da relação } \\
\text { entre autores produtores } \\
\text { e citados }\end{array}$ & $\begin{array}{l}\checkmark \quad \text { Discriminar os } \\
\text { vínculos e efeitos } \\
\text { institucionais decorrentes } \\
\text { da relação entre trajetória } \\
\text { científica dos autores } \\
\text { produtores e citados }\end{array}$ & $\begin{array}{l}\checkmark \quad \text { Identificar os } \\
\text { vínculos e efeitos } \\
\text { temáticos e } \\
\text { epistemológicos } \\
\text { decorrentes da relação } \\
\text { entre autores produtores } \\
\text { e citados }\end{array}$ \\
\hline $\begin{array}{l}\text { Métodos e } \\
\text { Técnicas }\end{array}$ & $\begin{array}{l}\checkmark \quad \text { Análise de } \\
\text { conteúdo; } \\
\checkmark \quad \text { Análise documental } \\
\checkmark \quad \text { Análise } \\
\text { historiográfica; e } \\
\checkmark \quad \text { Análise de } \\
\text { conjuntura. }\end{array}$ & $\begin{array}{l}\checkmark \quad \text { Análise de } \\
\text { conteúdo; } \\
\checkmark \quad \text { Análise documental; } \\
\checkmark \quad \text { Análise } \\
\text { historiográfica; e } \\
\checkmark \quad \text { Análise de } \\
\text { conjuntura. }\end{array}$ & $\begin{array}{l}\checkmark \text { Análise de assunto; } \\
\checkmark \quad \text { Análise de } \\
\text { conteúdo; } \\
\checkmark \quad \text { Análise documental; } \\
\checkmark \quad \text { Análise } \\
\text { historiográfica; e } \\
\checkmark \quad \text { Análise de } \\
\text { conjuntura }\end{array}$ \\
\hline Produtos & Visualização das & Determinação das & $\checkmark \quad$ Apresentação das \\
\hline
\end{tabular}




\begin{tabular}{l|l|l|l}
\hline & relações de dominação & relações de forças e de & $\begin{array}{l}\text { correntes hegemônicas } \\
\text { predominantes na }\end{array}$ \\
& entre autores produtores & poder entre grupos, & relação entre os recortes \\
& e citados; & segmentos e instituições; & temáticos, os autores \\
& $\checkmark \quad$ Explicitação de & $\checkmark \quad$ Demarcação do & produtores e citados; \\
desigualdades sociais na & nível das influências & $\checkmark$ Delimitação das \\
produção científica. & exercidas pelas & disputas ideológicas \\
& instituições na produção & presentes nas \\
& científica. & configurações temáticas \\
& & & dos campos. \\
\hline
\end{tabular}

Fonte: Elaborado pelos Autores (2016).

Em função dos fatores ideológicos e efeitos consagradores e reprodutivos que configuram os contextos culturais dos estudos de citação da concepção teórica apresentada e discutida, pontua-se que os julgamentos de valores devem ser minimizados, em detrimento de análises pautadas na conjuntura que orienta o universo a ser investigado. Desta feita, fica estabelecido o terceiro item do modelo multidimensional desta proposta, com base nas particularidades e singularidades que constituem os contextos culturais dos estudos de citação.

No tocante aos tópicos apontados que resultaram no desenho epistemológico para os estudos de citação, suas teorias, concepções e dimensões, o Quadro 3 apresenta sinteticamente a caracterização da especialidade temática.

Quadro 3 - Matriz epistemológica dos estudos de citações

\begin{tabular}{|c|c|c|c|c|}
\hline $\begin{array}{c}\text { Teorias e } \\
\text { Concepções }\end{array}$ & Dimensões & Objetos & Objetivos & Produtos \\
\hline Normativa & Produtiva & Referências & $\begin{array}{l}\text { Elaboração de } \\
\text { metodologias, índices, } \\
\text { indicadores e } \\
\text { representações }\end{array}$ & $\begin{array}{l}\text { Produção de rankings, } \\
\text { modelos de análises e } \\
\text { representações gráficas }\end{array}$ \\
\hline Construtivista & Discursiva & $\begin{array}{l}\text { Razões das } \\
\text { citações }\end{array}$ & $\begin{array}{l}\text { Levantamento, } \\
\text { categorização e } \\
\text { análise dos discursos } \\
\text { dos cientistas }\end{array}$ & $\begin{array}{l}\text { Definição dos hábitos } \\
\text { discursivos dos } \\
\text { cientistas e das } \\
\text { comunidades científicas }\end{array}$ \\
\hline \multirow{3}{*}{ Sociocultural } & Temática & $\begin{array}{l}\text { Recortes } \\
\text { temáticos das } \\
\text { citações }\end{array}$ & \multirow{3}{*}{$\begin{array}{l}\text { Identificação das } \\
\text { relações de produção } \\
\text { e distinção em } \\
\text { comunidades } \\
\text { científicas }\end{array}$} & \multirow{3}{*}{$\begin{array}{l}\text { Visualização das } \\
\text { relações entre produção } \\
\text { e consagração } \\
\text { sustentadas e mantidas } \\
\text { pelas comunidades } \\
\text { científicas }\end{array}$} \\
\hline & Institucional & $\begin{array}{l}\text { Formação e } \\
\text { atuação dos } \\
\text { autores }\end{array}$ & & \\
\hline & Social & $\begin{array}{l}\text { Relações sociais } \\
\text { entre os autores }\end{array}$ & & \\
\hline
\end{tabular}

Fonte: Elaborado pelos Autores (2016).

Em decorrência dos argumentos levantados e discutidos ao longo do texto, em que foram demarcadas as teorias e concepções e suas dimensões, defende-se a delimitação dos estudos de citação como uma especialidade temática que intercruza elementos teóricos e metodológicos da Comunicação Científica, da Ciência da Informação e dos Estudos Métricos. Dessa forma, exibe-se a Figura 2 que ilustra e explica as relações presentes do modelo multidimensional dos estudos de citação como uma especialidade científica.

Figura 2 - Modelo multidimensional dos estudos de citação 


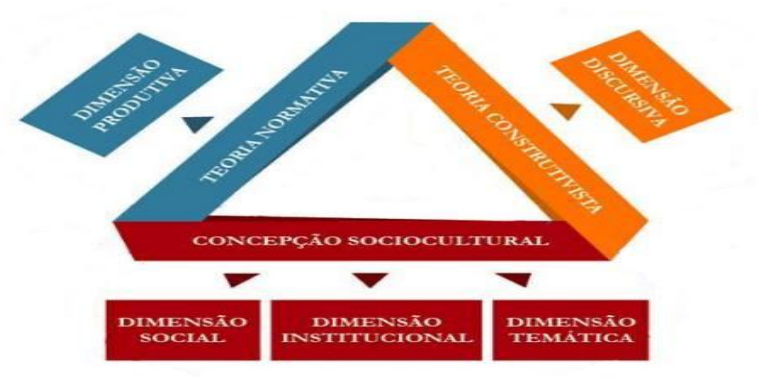

Fonte: Elaborado pelos Autores (2016).

O modelo proposto tem como finalidade a apresentação de um esquema analítico a ser aplicado em futuras investigações que busquem visualizar as formas de produção e as instâncias de distinção em campos e domínios científicos. Cada dimensão está voltada para a demarcação teórica e metodológica dos fenômenos destacados, em que as citações e referências estão circunscritas na lógica da edição certificada como insumos e produtos cientificamente dotados de elementos simbólicos. Além disso, é função do modelo delineado enfatizar as influências teóricas de Bourdieu sobre a dinâmica que governa os campos e domínios da ciência, na perspectiva dos confrontos entre os grupos sociais constituídos.

\section{Considerações finais}

O dimensionamento dos estudos de citação como uma especialidade temática dotada de elementos científicos próprios e compartilhados com outros campos e domínios, permitiu a esta investigação propor um modelo multidimensional que se volta às práticas de citação. Ao mesmo tempo, determinou que as relações de produção e citação não podem ser analisadas separadamente, tendo em vista os contextos socioculturais que incidem em tais práticas. E por fim, sugeriu outros componentes que, historicamente, não costumavam ser contemplados dentro do circuito analítico das pesquisas desenvolvidas, em especial às circunstâncias sociais e culturais de produção e citação dos pesquisadores em seu fazer científico.

Como sugestões metodológicas de aplicação do modelo multidimensional proposto para os estudos de citação, destacam-se as seguintes relações:

a) a dimensão produtiva da teoria normativa se relaciona diretamente com as dimensões institucional e social da concepção sociocultural;

b) a dimensão discursiva da teoria construtivista se relaciona com mais ênfase à dimensão temática da concepção sociocultural;

c) as análises das práticas de citação pela orientação sociocultural devem ser iniciadas pela dimensão temática, por situar epistemologicamente os autores, 
as instituições e as posições na configuração dos campos e domínios;

d) as relações teóricas e as operações metodológicas entre as dimensões propostas para as teorias e concepções devem ser implementadas de forma integrada, com a admissão de avanços e recuos necessários para o alcance dos objetivos de pesquisa estabelecidos.

\section{Referências}

BORNMANN, L.; DANIEL, H.-D. What do citation counts measure? a review of studies on citing behavior. Journal of Documentation, v. 64, n. 1, p. 4579, 2008.

BOURDIEU, P. O campo científico. In: ORTIZ, R. (Org.). Pierre Bourdieu. São Paulo: Ática, 1983. cap. 4, p.122-155.

BOURDIEU, P. A distinção: crítica social do julgamento. São Paulo: EDUSP; Porto Alegre: Zouk, 2011a.

BOURDIEU, P. A economia das trocas simbólicas. São Paulo: Perspectiva, 2011b.

BOURDIEU, P. Homo academicus. 2. ed. Florianópolis: Ed. da UFSC, 2013.

BOURDIEU, P. Os usos sociais da ciência: por uma sociologia clínica do campo científico. São Paulo: Ed. UNESP, 2004.

BOURDIEU, P.; PASSERON, J. A reprodução: elementos para uma teoria do sistema de ensino. Petrópolis: Vozes, 2012.

COOL, C. The concept of situation in information science. Annual Review of Information Science and Technology, Baltimore County, v. 35, p. 5-42, 2001.

COURTRIGHT, C. Context in information behavior research. Annual Review of Information Science and Technology, Baltimore County, v. 41, n. 7, p. 273-306, 2007.

CRONIN, B. The need for a theory of citing. Journal of Documentation, $\mathrm{v}$. 37, n. 1 , p. 16-24, 1981.

CRONIN, B. The citation process: the role and significance of citations in scientific communication. London: Taylor Graham, 1984.

CRONIN, B. Metatheorizing citation. Scientometrics, Amsterdam, v. 43, n. 1 , p. 45-55, 1998.

DAVIS, P. M. Reward or persuasion?: The battle to define the meaning of a citation. Learned Publishing, v. 22, p. 5-11, 2009.

ERIKSON, M. G.; ERLANDSON, P. A taxonomy of motives to city. Social Studies of Science, v. 44, n. 1, p. 1-13, 2014. 
LEYDESDORFF, L. The communication of meaning and the structuration of expectations: Giddens' "structuration theory" and "Luhmann's "selforganization." Journal of the American Society for Information Science and Technology, Maryland, v. 61, n. 10, p. 2138-2150, 2010.

LEYDESDORFF, L. Towards a theory of citation? Scientometrics, Amsterdam, v. 12, n. 5/6, p. 305-309, 1987.

LEYDESDORFF, L. Theories of citation? Scientometrics, Amsterdam, v. 43, n. 1, p. 5-25, 1998.

LEYDESDORFF, L. A sociological theory of communication: the self organization of the knowledge-based society. Parkland, FL: Universal Publishers, 2001.

LEYDESDORFF, L.; WOUTERS, P. Between texts and contexts: advances in theories of citation?: (a rejoinder). Scientometrics, Amsterdam, v. 44, n. 2, p. 5-25, 1999.

LIEVROUW, L. A. New media and the 'pluralization of life-worlds'. New Media \& Society, v. 3, p. 7-28, 2001.

NICOLAISEN, J. Citation analysis. Annual Review of Information Science and Technology, Baltimore County, v. 41, p. 609-641, 2007.

RIVIERA, E. Scientific communities as autopoietic systems: the reproductive function of citations. Journal of the American Society for Information Science and Technology, v. 64, n. 7, p. 1442- 1453, 2013.

THOMPSON, J. B. Ideologia e cultura moderna: teoria social crítica na era dos meios de comunicação de massa. Petrópolis: Vozes, 1995.

WOUTERS, P. The citation culture. 1999. 278f. Tese (Doutorado em Ciências) - University of Amsterdan, Amsterdan, 1999. 